\title{
Sorting of proteins to vacuoles in plant cells
}

\author{
Jean-Marc Neuhaus ${ }^{1}$ and John C. Rogers ${ }^{2, *}$ \\ ${ }^{1}$ Laboratoire de Biochimie, Institut de Botanique, Université de Neuchâtel, 9 rue Emile-Argand, 2007 Neuchâtel 7 , \\ Switzerland; ${ }^{2}$ Institute of Biological Chemistry, Washington State University, Pullman, WA 99164, USA (*author \\ for correspondence)
}

Key words: propeptide, receptor, secretory pathway, tonoplast, protein sorting

\begin{abstract}
An individual plant cell may contain at least two functionally and structurally distinct types of vacuoles: protein storage vacuoles and lytic vacuoles. Presumably a cell that stores proteins in vacuoles must maintain these separate compartments to prevent exposure of the storage proteins to an acidified environment with active hydrolytic enzymes where they would be degraded. Thus, the organization of the secretory pathway in plant cells, which includes the vacuoles, has a fascinating complexity not anticipated from the extensive genetic and biochemical studies of the secretory pathway in yeast. Plant cells must generate the membranes to form two separate types of tonoplast, maintain them as separate organelles, and direct soluble proteins from the secretory flow specifically to one or the other via separate vesicular pathways. Individual soluble and membrane proteins must be recognized and sorted into one or the other pathway by distinct, specific mechanisms. Here we review the emerging picture of how separate plant vacuoles are organized structurally and how proteins are recognized and sorted to each type.
\end{abstract}

\section{Organization of the secretory pathway}

All eukaryotic cells assemble their secretory pathway into a series of organelles as a means of defining compartments with distinct functions (reviewed by [83]). The secretory pathway begins with the endoplasmic reticulum (ER). In general, soluble proteins that enter the secretory pathway are co-translationally inserted across the ER membrane during their synthesis on membrane-bound ribosomes. A newly synthesized protein in the ER lumen will be retained in, or directed to, a specific organelle within the pathway depending upon information contained within its polypeptide chain, information encoded both by specific amino acid sequences and by determinants formed from its three-dimensional structure as the protein folds into a stable conformation with the assistance of ER chaperone proteins (Sengupta-Gopalan and Galili, this volume). An as yet poorly understood process selects certain proteins for export from the ER [3, 4, 72] and concentrates them into vesicles that transport them to cis-Golgi cisternae [105] (Figure 1). After exiting the
$\mathrm{ER}$, a protein that lacks specific information for retention or sorting to a particular secretory organelle will pass through the Golgi complex and be packaged into poorly characterized vesicles that fuse with the plasma membrane and release the protein to the cell exterior, the so-called default pathway [21, 87] (Figure 1). Our discussion will focus on structural features of proteins that direct them instead to pathways leading to vacuoles. As these structural features determine the fate of a protein by actively directing it to a specific pathway and destination, we will refer to them as "vacuolar sorting determinants' (VSDs).

\section{Complexity of vacuoles in plant cells}

Plant cell vacuoles have long been known to have many different functions [8, 121]. For example, they may contain hydrolytic enzymes that function in an acid environment [7, 67]. They may contain concentrations of secondary metabolic products such as alkaloids, glycosides and glutathione conjugates, organic 


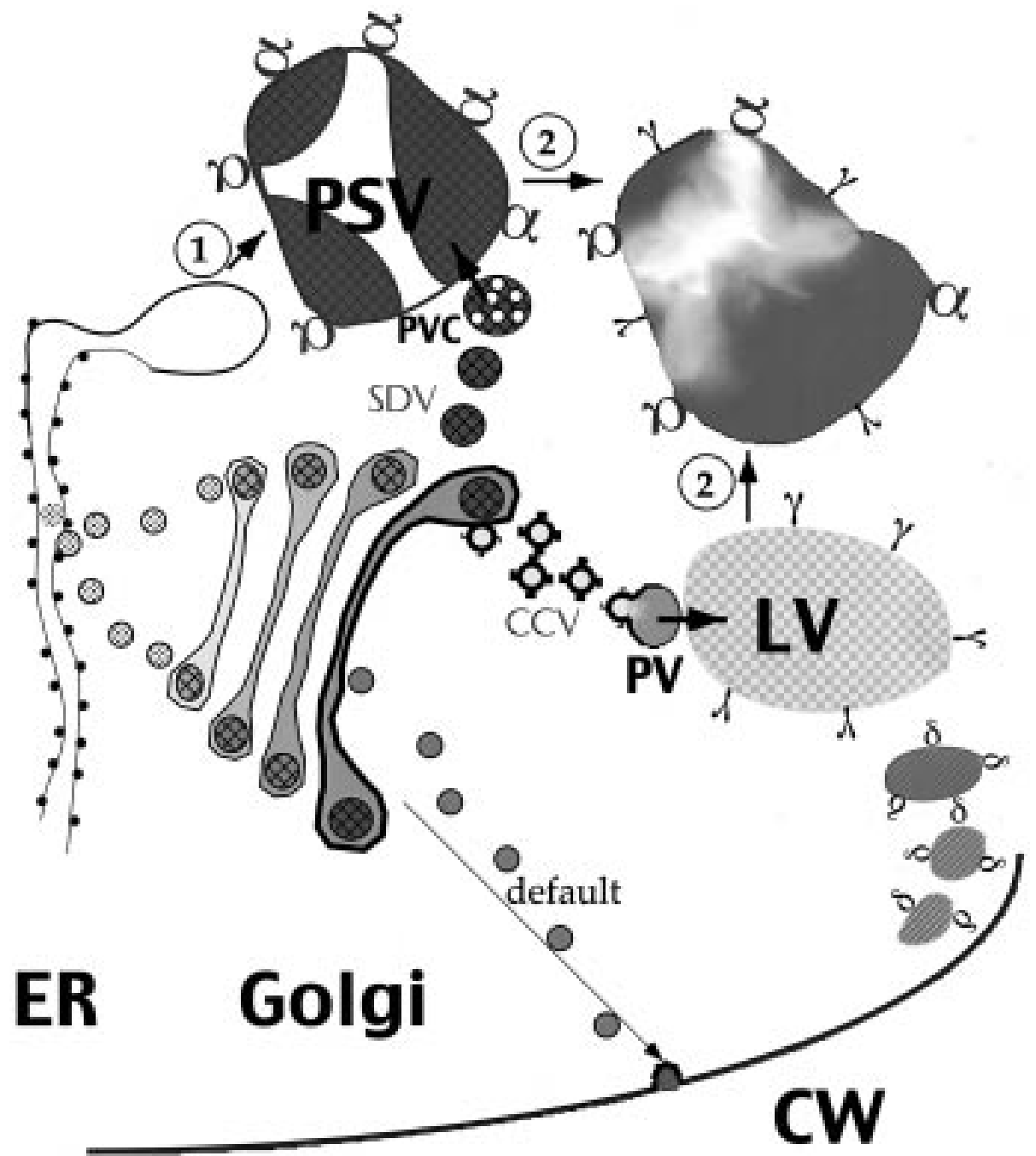

Figure 1. The plant secretory and vacuolar systems. Indicated are endoplasmic reticulum (ER), Golgi, cell wall (CW), protein storage vacuole (PSV) and lytic vacuole (LV). Two subdomains [104] are shown for the ER: rough ER where membrane-bound ribosomes synthesize proteins for translocation into the ER, and a region of smooth ER where PSV tonoplast may originate, indicated by the thick blue line. The arrow denoted by the circled 1 indicates the possibility of direct traffic of proteins between such regions of ER and the PSV, as suggested from morphologic studies [92] as well as studies of $\alpha$-TIP traffic discussed in the text. The grey sphere within the rough ER indicates that proteins destined for export to the Golgi are somehow selected and concentrated as part of the process of being packaged into vesicles (grey-filled circles). Golgi cisternae are shown with dilated ends containing protein inclusions (blue-filled circles) that become more electron opaque in a cis (lightest) to trans (darkest) direction. Smooth dense vesicles (SDV) carry soluble proteins from Golgi to a prevacuolar compartment [39, 100] (PVC) that, in developing pea cotyledons, appears as a multivesicular structure. This PVC appears to transfer its contents to the PSV by direct fusion with that structure [39]. The blue color of the SDV matches that of the Golgi inclusions and the protein bodies within the PSV to indicate the theory that Golgi inclusions represent proteins in the process of aggregation as a mechanism for sorting into SDV, and that this process contributes to the generation of the condensed protein body structure [83]. This may also correspond to the wortmannin-sensitive pathway used by proteins with a ctVSD. The as yet uncharacterized vesicles that carry soluble proteins lacking targeting information in the default pathway to fusion with the plasma membrane are indicated in dark green. Clathrin coated vesicles (CCV) that carry soluble proteins selected by members of the plant vacuolar sorting receptor (VSR) family to the lytic prevacuolar compartment (PV; [85]) are shown in yellow, and the thick black lines around a Golgi cisterna, CCV and PV indicates the organelles where VSR protein has been identified. The Greek letters indicate specific vacuole types identified because they carry a specific TIP in their tonoplast: $\alpha$ for $\alpha$-TIP on PSV, $\gamma$ for $\gamma$-TIP on LV, and $\delta$ for $\delta$-TIP on other vacuoles whose function and biogenesis have not yet been determined. 
acids, and anthocyanins [7, 62, 121]. They may store proteins; vacuolar storage proteins are most prominent in seeds but may also occur in many different vegetative tissues [27, 31, 32, 106]. Previous concepts of vacuole biogenesis and function hypothesized that protein storage vacuoles represented portions of the central vacuole that subdivided as deposits of storage protein accumulated [17, 115]. It is now clear, however, that vacuoles with proteases active at low $\mathrm{pH}$ (so-called lytic or vegetative vacuoles) and protein storage vacuoles are structurally and functionally distinct organelles $[44,86]$. On one hand, separation of function into two separate compartments simplifies the biochemistry and physiology of how protein storage could occur because it presumably would protect storage proteins from exposure to an environment where they would be degraded. On the other hand, the cell biology of vacuole biogenesis and maintenance, and of protein sorting, is vastly more complicated [91]. In contrast to yeast cells, which have a single lytic vacuole, plant cells must generate several biochemically and structurally distinct types of tonoplast membranes and must maintain these membranes as separate entities. Additionally, they must have distinct and separate vesicle pathways leading to protein storage and lytic vacuoles. Finally, they must have mechanisms that sort storage proteins to one pathway and hydrolytic enzymes to the other.

\section{Vacuole biogenesis and the role of tonoplast intrinsic proteins}

Ultimately all membranes within a cell derive from lipid synthesized in the ER, but relatively little is known about which organelles directly contribute membrane lipid to form tonoplast membranes. Two general models have been offered [91]. In one, vacuoles are proposed to originate from a Golgiassociated tubular network of membranes [64, 65]. An alternative model suggests that vacuoles originate directly from ER [11, 37, 91, 104]. This question is relevant to the subject of our review because integral membrane proteins must also be synthesized and transported to the proper tonoplast, and it is likely that the paths they follow to their destination reflect those used for the biogenesis of the tonoplasts themselves.

Studies of vacuole function and biogenesis were greatly assisted by the finding that plant vacuole tonoplast contains abundant integral membrane proteins with six transmembrane-spanning regions called tonoplast intrinsic proteins (TIPs) [53]. TIPs belong to a family of proteins that function as aquaporins, channels to transport water [14], and the sequences of TIPs are homologous with but differ from the sequences of other members of the family that are found in plasma membranes [119]. It has been proposed that TIPs are present in tonoplast because aquaporins are required to maintain vacuole function [14]. However, TIPs are very abundant proteins. In radish tap root, $\gamma$-TIP makes up $30-50 \%$ of total tonoplast protein, while vacuolar pyrophosphatase and $\mathrm{H}^{+}$-ATPase enzymes account for only about $10 \%$ of tonoplast protein [36]. This abundance of $\gamma$-TIP would seem to be in excess of the amount needed for water transport and suggests a structural function for the protein (M. Maeshima, personal communication). It is interesting to observe that the Saccharomyces cerevisiae genome contains genes encoding members of the MIP family, to which TIPs belong, and aquaporins should be essential for yeast vacuole function, but these proteins are not known to be abundant in the yeast vacuole membrane [50, 58, 89]. While yeasts have only one functional type of vacuole, plant cells have several and a specific isoform of TIP is associated with a specific functional type (see below). We hypothesize that, in plant cells, the presence of a specific TIP isoform is required for the biogenesis of a specific vacuole type, and that the specific TIP isoform is recognized and bound by proteins that form a defined cytoplasmic coat (G.-Y. Jauh and J.C. Rogers, unpublished data). The cytoplasmic coat would then prevent fusion of tonoplast from one type of vacuole with another, thereby maintaining the integrity of functionally different vacuolar compartments. In this model, then, a specific TIP isoform is required for, and defines, the specific structure and function of a vacuole.

\section{TIP isoforms define functionally distinct vacuoles}

Initially, different isoforms of TIPs were thought to be expressed in a tissue-specific manner, with $\alpha$ TIP being seed-specific and $\gamma$-TIP being expressed in vegetative tissues [43]. The availability of antibodies to purified $\alpha$-TIP [53] and to tonoplast enriched in $\gamma$-TIP (TIP-Ma27 antibodies [66]) made possible experiments to define the function of vacuoles carrying those antigens. These experiments demonstrated that $\alpha$-TIP was specifically present in protein storage vacuole (PSV) tonoplast, while the TIP-Ma27 antibodies identified vacuoles with active proteases and acidic $\mathrm{pH}$, termed lytic or vegetative vacuoles (LV) $[44,86]$. The abundance of $\alpha$-TIP in seeds reflected the abun- 
dance of PSV there, but $\alpha$-TIP was also present in protein storage vacuoles (PSVs) in root tip cells that contained barley lectin as a storage protein [86]. Interestingly, a single cell in pea or barley root tips could contain vacuoles labeled separately with both $\alpha$-TIP and TIP-Ma27 [86]. In some cases, vacuoles labeled with both antibodies were identified; these presumably represented cells where the two separate vacuolar compartments had been merged, presumably to expose storage proteins to an environment where their degradation could proceed [86].

The TIP-Ma27 antiserum had been raised to beetroot tonoplast membranes [66]; thus, it was possible that the immunofluorescence labeling patterns observed $[66,86]$ were due to reactivity of the antibodies with more than one tonoplast protein. To clarify the distribution of different TIP isoforms within plant cells, we have prepared anti-peptide antibodies specific for the carboxy-terminal amino acid sequences of $\alpha-, \gamma-$, and $\delta$-TIP (G.-Y. Jauh, T.E. Phillips, and J.C. Rogers, unpublished data). In immunofluorescence experiments with pea root tip cells, the anti- $\alpha$-TIP peptide antibodies co-localize with antibodies raised to purified $\alpha$-TIP [53] and the anti- $\gamma$-TIP peptide antibodies co-localize with antibodies to purified $\gamma$-TIP from radish [36]. The anti- $\delta$-TIP peptide antibodies, however, identify a separate population of vacuoles present in cells that also contain vacuoles labeling with anti- $\alpha$-TIP or anti- $\gamma$-TIP. While the latter tend to be larger and in a more central location in cells, $\delta$-TIP vacuoles are smaller and more frequently localized in the cell periphery, in some cases immediately beneath the plasma membrane (unpublished data). Some of these $\delta$-TIP vacuoles also contain protein labeled with anti-arabinogalactan antibodies (unpublished data). The latter finding would be consistent with a role in endocytosis ([33], and Griffing, this volume). Our preliminary model for the organization of these three types of vacuoles is presented in Figure 1.

Antibodies to the C-terminal peptide sequence of an additional TIP isoform, initially identified as DIP from Antirrhinum [18], do not cross-react with the other TIP peptides and identify small organelles in rare root tip cells (G.-Y. Jauh and J.C. Rogers, unpublished data). It will be of some interest to clarify the nature of these organelles. The presence of four TIP isoforms, $\alpha-, \gamma-$, and $\delta$-TIP and DIP, is consistent with the findings of Weig et al. [119] who used northern blot hybridization with expressed sequence tag (EST) clones to catalogue all of the TIP isoforms expressed in Arabidopsis. Their nucleotide sequence dendrogram of TIP gene families has, however, some uncertainties because raw sequences from the EST clone database were apparently used for comparisons. Some of these sequences (e.g. GenBank T22237 and T21060) have not only regions with multiple frameshifts and numerous unread bases but also $5^{\prime}$ fusions of ca. 60 nucleotides that are unrelated to TIP gene sequences. When these regions are discarded, the readable portions of T22237 and T21060 are 80\% and $84 \%$ identical to $\gamma$-TIP, respectively. Additionally, EST clone Z18142 is a DIP homologue. When these corrections are applied to the data [119], TIP gene family members that are expressed at measureable levels in Arabidopsis are $\alpha-, \gamma-$, and $\delta$-TIP and DIP. Mechanisms for sorting of soluble proteins to $\alpha$ TIP PSV and to $\gamma$-TIP LV have been identified (see below, and Robinson, this volume). The functional nature of, and mechanisms for, delivery of proteins to $\delta$-TIP vacuoles and to vacuoles marked by the presence of DIP should be of considerable interest to plant cell biologists. A unique type of autophagic vacuole accumulates in nutrient-starved tobacco suspension culture cells when the activity of intracellular cysteine proteases is inhibited [73], and its associated TIP isoform has not yet been identified. Swanson et al. [109] have identified a vacuole type in barley aleurone cells with some characteristics similar to those of autophagic vacuoles. These secondary, lysosome-like vacuoles were distinct from protein storage vacuoles but, interestingly, had in common with PSVs the presence of $\alpha$-TIP in their tonoplast. This classification of vacuole types based on their complement of TIP proteins is even more complicated when one considers that vacuoles can be identified where $\alpha$ - and $\gamma$-TIP, $\gamma$ and $\delta$-TIP, and $\alpha$ - and $\delta$-TIP are both present in the same tonoplast ([86], and unpublished data).

\section{Sorting of soluble proteins to vacuoles}

Three types of vacuolar sorting determinants have been identified. One type, described in the N-terminal propeptides of sweet potato prosporamin and barley proaleurain, was termed an NTPP determinant; a second type, described in the $\mathrm{C}$-terminal propeptides of barley lectin and tobacco chitinase, was termed a CTPP determinant; and a third type, described for certain seed storage proteins, was termed an internal determinant $[15,74]$. Each determinant has subsequently been shown to have specific physical and functional characteristics that define it. The N- 
terminal propeptide determinants require a conserved amino acid sequence probably recognized by a sorting receptor for their function and may function when placed elsewhere in the protein; for that reason we suggest the term 'sequence-specific VSD' (ssVSD) to describe them. In contrast, the C-terminal propeptide determinants have little or no discernable requirement for a conserved sequence, but the weight of evidence suggests that they must be placed at the C-terminus of a protein; for that reason we suggest the term ' $\mathrm{C}$ terminal VSD' (ctVSD) to describe them. Finally, the internal determinants of storage proteins have been very difficult to study and it has not been possible to define any conserved amino acid sequence involved in their function. Indeed, it is likely that in many cases the physical structure of a storage protein, including its three dimensional structure and propensity to form aggregates plays a major role in directing it into a pathway to the protein storage vacuole; for that reason we suggest the term 'physical structure VSD' (psVSD) to describe this type of sorting determinant.

\section{The sequence-specific vacuolar sorting determinants (ssVSD)}

The ssVSD was first defined in the propeptides of sweet potato prosporamin and barley proaleurain.

\section{Vacuolar sorting of prosporamin}

Sporamin is an abundant storage protein in sweet potato tubers [60]. Storage proteins from tubers are classed with vegetative storage proteins and differ substantially from seed storage proteins in their physical structure and patterns of storage [106]. For example, although vegetative storage proteins are stored in vacuoles they do not form protein bodies. The TIP isoform present in those vacuoles has not yet been determined. Additionally, several have been shown to be active enzymes; patatin, the major storage protein from potato tubers, is an esterase [94]. The fact that the mechanism for sorting prosporamin to vacuoles appears to be specific for the lytic vacuole pathway indicates the liklihood that sporamin is stored in vacuoles with characteristics of LVs rather than PSVs.

After cleavage of the signal peptide, prosporamin carries a 16 amino acid $\mathrm{N}$-terminal propeptide that is removed to form mature sporamin in sweet potato tubers [69]. When expressed in tobacco suspension culture cells, sporamin is sorted to the vacuole. Expres- sion of a mutant lacking the propeptide resulted in secretion of sporamin, demonstrating that the propeptide contains essential vacuolar sorting determinants [70]. When four amino acid deletions were made within the propeptide sequence beginning at His-22, two regions (indicated by single and double underlines, respectively) were shown to be essential for efficient sorting to the vacuole: HSRFNPIRLPTTHEPA [75]. A singleresidue mutation of Asn-26 to Gly caused about $40 \%$ of the expressed protein to be secreted, while the mutation of Ile-28 to Gly essentially abolished proper sorting to the vacuole [75]. An amino acid with a large alkyl side-chain at Ile-28 is essential for proper function of the sorting determinant and substitution with similar residues such as Leu maintain function [59]. Thus, although Ile is an essential residue, it must be present within the context of the sequence SRFNPIRL, and those eight amino acids define the minimum VSD. Potato protease inhibitors related to sporamin have a similar motif $\mathrm{S}(\mathrm{Q} / \mathrm{K}) \mathrm{N}(\mathrm{P} / \mathrm{L}) \mathrm{I}(\mathrm{N} / \mathrm{D}) \mathrm{LP}(\mathrm{S} / \mathrm{T})$ [51]. It is interesting that the motif NLPS was also identified in storage $2 \mathrm{~S}$ albumins as a binding motif for a putative vacuolar sorting receptor (see below; [100]). It is important to note that the prosporamin propeptide, when attached to the N-terminus of barley lectin lacking a C-terminal propeptide and expressed in tobacco suspension culture cells, functioned as an efficient VSD for that chimeric protein [68]. Thus the VSD is defined by sequences within the propeptide and probably does not depend upon contributions from the mature protein sequence for its function. The prosporamin ssVSD functioned efficiently when placed at the C-terminus of sporamin [59], demonstrating that the amino acid sequence and not its location on the protein is the most important feature of the VSD.

\section{Vacuolar sorting of proaleurain}

Barley aleurain is a cysteine protease closely related to mammalian cathepsin $\mathrm{H}$ [48]. It is synthesized as a proenzyme and transported to an acidified, post-Golgi compartment where it is processed to its mature form [45]. In barley aleurone cells essentially all detectable aleurain is in its mature form, the two enzymes that process proaleurain both have $\mathrm{pH}$ optima near 5 [45], and purified aleurain enzyme has a $\mathrm{pH}$ optimum near 5 [47]. Aleurain was localized by immunoelectron microscopy to 'aleurain-containing vacuoles' in aleurone cells that were morphologically and physically distinct from protein storage vacuoles [45]. These facts all argue strongly for proaleurain to be sorted to an acidified 
vacuolar compartment with active proteases, and we have used aleurain as a marker to define lytic vacuoles [86].

When the sequences of proaleurain and the proenzyme form of a cysteine protease that is secreted from barley aleurone cells were compared, it appeared that the proaleurain propeptide had an $\mathrm{N}$-terminal extension $[46,48]$. An experimental strategy was designed to test the possibility that these 'extra' amino acids represented the vacuolar sorting determinants for proaleurain. Chimeric proteins were expressed in tobacco suspension culture protoplasts where reciprocal changes were made in proaleurain and the secreted protease: a portion of the proaleurain prosequence was substituted for the corresponding secreted protease sequence, and vice versa. Thus, if an essential part of the proaleurain VSD was removed, the mutated proaleurain would be secreted (loss of function), while the corresponding substitution into the secreted protease would cause it to be sorted to the vacuole (gain of function). Results from these experiments demonstrated that the immediate N-terminus of proaleurain, SSSSFADSNPIRPVTDRAAST, comprised an efficient VSD [46]. Interestingly, the determinant functioned with greatest efficiency when present as an intact sequence, but substitution of the shorter sequences SSSSFADS, SNPIRP, and VTDRAAST onto the secreted protease resulted in vacuolar sorting with a lower efficiency. Thus it appeared that interactions among these three portions of the larger sequence contributed to a highly efficient VSD [46]. This region of the prosequence is highly conserved among aleurain homologues from other monocotyledonous and dicotyledonous species; comparison of the different sequences indicated the following consensus sequence for the most highly conserved residues: FXDSNPIRXV(S/T)D [93].

Comparison of the prosporamin and proaleurain VSDs demonstrated the presence of a conserved NPIR central motif. The presence of an essential conserved sequence within sorting determinants from two completely different types of proteins suggested that the sequence might be recognized by a receptor that would, in turn, be responsible for directing the proteins into the proper pathway to the LV.

\section{Identification and cloning of a probable vacuolar sorting receptor}

A sorting receptor would have several structural and functional characteristics that could be predicted (for a review, see [91]): It would be a transmembrane protein with the ligand binding domain within the lumen of the Golgi, where ligand binding would occur at a near-neutral $\mathrm{pH}$. The cytoplasmic tail would be recognized by proteins responsible for assembling the receptor into vesicles that would bud from the Golgi and carry receptor plus cargo to a destination. For vacuolar sorting, the destination would have an acidic $\mathrm{pH}$ that would cause dissociation of the receptor-ligand complex. As clathrin coated vesicles (CCVs) were known to function in traffic from Golgi to the lysosome/vacuole in mammalian and yeast cells, and as they similarly had been associated with transport of hydrolases to plant vacuoles [29], we developed an experimental strategy to search for a ssVSD-binding receptor in membranes purified from $\mathrm{CCV}$ s from developing peas [54].

Two affinity columns were constructed, one with a peptide representing the proaleurain VSD and the other with a peptide representing the corresponding region of the barley secreted protease. Lysates of pea $\mathrm{CCV}$ membranes were passed through the columns and, after extensive washing, adherent proteins were released with a pH 4 buffer [54]. A single ca. $80 \mathrm{kDa}$ protein, identified as BP-80, bound to the proaleurain column but not to the control column. Treatment of the vesicles with protease prior to lysis and column purification resulted in ca. $5 \mathrm{kDa}$ shortening of BP80; the N-terminal amino acid sequences of intact and protease treated forms were identical, indicating that the $\mathrm{N}$-terminus was within the vesicle lumen while ca. $5 \mathrm{kDa}$ of $\mathrm{C}$-terminal sequence was exposed on the cytoplasmic side. Analyses of other membrane fractions from gradients used to purify the CCVs identified a lower density fraction where BP-80 comprised ca. $50 \%$ of the protein. Although the organelle(s) from which this lower density membrane fraction originated have not been identified, it served as an optimal source of BP-80 for further characterization. An in vitro assay was developed where binding of proaleurain peptide labeled with $\left[{ }^{125} \mathrm{I}\right]$ to BP-80 could be quantitated. The proaleurain peptide was bound with a $k_{d}$ of $37 \mathrm{nM}$; binding was optimal at $\mathrm{pH}$ 6.0-6.5 and was abolished at $\mathrm{pH}<5.0$ [54]. A peptide representing the prosporamin VSD, SRFNPIRLPT, competed weakly with the proaleurain peptide for binding, but a peptide with the essential Ile mutated to Gly, SRFNPGRLPT, did not compete for binding. A peptide representing the C-terminal propeptide of barley lectin also did not compete for binding [54]. 
Subsequent studies used different peptide affinity columns to assess binding of BP-80 from less dense membrane lysates [55]. These results confirmed binding to proaleurain and prosporamin peptides and demonstrated lack of binding to the prosporamin peptide with Ile $\rightarrow$ Gly mutation and to the barley lectin propeptide sequence. Together, results from the two studies correlated binding of BP-80 to sequences in proaleurain and prosporamin that are functional VSDs, while mutated sequences that do not function as VSDs did not bind. They also demonstrated the inability of a ctVSD to be bound by BP-80. Additionally, in the second study, binding was observed to peptides representing the $\mathrm{C}$-terminus of Brazil nut $2 \mathrm{~S}$ albumin; the minimal sequence capable of being bound represented the $\mathrm{C}$-terminal propeptide and 5 adjacent amino acids of the mature protein [55]. These residues were stated to be part of a determinant that, when fused to yeast invertase, caused the enzyme to be sorted to the vacuole in tobacco cells [55]. Caution should be used, however, in extrapolating these binding data to a conclusion that a receptor protein similar to BP-80 may be involved in vacuolar sorting of the $2 \mathrm{~S}$ albumin protein. It is not known if the required residues in the mature $2 \mathrm{~S}$ albumin molecule adjacent to the propeptide would be physically accessible to another protein. Indeed, these include a Cys residue that is highly conserved among related plant $2 \mathrm{~S}$ albumins [100] that probably participates in an intramolecular disulfide bond. Additionally, expression of chimeric fusion proteins in the plant secretory system may frequently and unpredictably lead to proteins that cannot fold properly [48] and therefore have the potential to undergo aggregation. As noted below, aggregation itself may be a mechanism for vacuolar sorting that would be independent from a receptor-mediated process. It is also of interest that the $2 \mathrm{~S}$ albumin peptide that binds BP-80 in the assay does not contain a sequence homologous to the NPIR motif. This may reflect a heterogeneity in binding preferences by BP-80. The possibility that a receptor interacting with the proaleurain ssVSD might have broad ligand binding specificity was indicated by the finding that both SSSFADS and SNPIRP alone functioned as vacuolar targeting determinants, albeit with lower efficiency than when together [46]. Such binding heterogeneity could result from the presence of several different binding sites within the protein (see below), as is known for the Man-6-P /IGF II receptor [20]. Alternatively, recognition of different ligand sequences could be due to other receptor proteins, BP-80 homologues, in the starting preparation.
In yeast, some proteins that are able to exit the ER even though they contain regions that are not properly folded are sorted to the vacuole by the same receptor responsible for bona fide targeting of CPY [49]. Perhaps BP-80 could play a similar role of scavenging improperly folded proteins to the lytic vacuole if they should escape the 'quality control' in the ER. In this case, fusion of a truncated protein to a reporter protein might expose structures typical of improper folding and might cause vacuolar sorting by a mecanism different to the mecanism used by the complete protein.

Shimada et al. [100] identified two proteins of 72 and $82 \mathrm{kDa}$ in preparations of storage protein 'precursor accumulating vesicles' from developing pumpkin cotyledons that are homologues to BP-80. (The relationship between precursor accumulating vesicles and dense vesicles thought to transport storage proteins to the PSV is discussed by Robinson, this volume.) Affinity columns carrying either the proaleurain VSD peptide, or other peptides representing portions of the pumpkin $2 \mathrm{~S}$ albumin precursor protein selected the $72 / 82 \mathrm{kDa}$ proteins from lysates of membranes from developing pumpkin cotyledon microsomes. The authors used a combination of affinity chromatography with different peptide columns plus competition for binding with soluble peptides to study the sequence specificity of binding for different sequences. A peptide, MRGIENPWRREG, representing the $2 \mathrm{~S}$ albumin internal propeptide bound the $72 / 82 \mathrm{kDa}$ proteins, and deletion of PWRREG or mutation of the sequence to MRGIENPWgggG abolished binding, while replacement of NPWR by GGGG had no effect. This motif is likely to be exposed on the surface of the $2 \mathrm{~S}$ albumin precursor since it contains a processing site. A second peptide, KARNLPSMCGIRPQRCDF, representing the $\mathrm{C}$-terminus of the $2 \mathrm{~S}$ albumin protein, also bound the $72 / 82 \mathrm{kDa}$ proteins, and mutation of the sequence to KARggggMCGIRPQRCDF abolished binding. A N(L/I)PS motif is found in most $2 \mathrm{~S}$ albumin precursors as well as in the $\mathrm{N}$-terminal propeptide of several potato protease inhibitors where it overlaps the NPIN motif [51]. These results [100] demonstrate the ability of homologues of BP-80 to bind peptides that do not share any apparent sequence conservation, and the authors suggest that possibly binding is dependent upon physicochemical properties of the peptides. The experiments, however, do not define binding affinities for the different ligands, and the affinity column assay method probably would permit retention by sequences with low binding affinities, rel- 
ative to the $37 \mathrm{nM} k_{d}$ for binding of BP-80 to the proaleurain VSD peptide. Additionally, the finding of the $72 / 82 \mathrm{kDa}$ proteins in the precursor accumulation vesicle preparations cannot, without more data, be interpreted to mean that those proteins function as receptors to direct storage proteins to their destination in the PSV. There is no assurance that the vesicle preparations represent a purified population from one organelle; indeed, a relatively small contamination with membranes corresponding to the less dense membrane fraction in developing pea cotyledons [54] could explain the presence of the $72 / 82 \mathrm{kDa}$ proteins.

Using amino acid sequence data from the $\mathrm{N}$ terminus and two internal tryptic peptides from BP-80, we identified an Arabidopsis EST clone, Z38123, representing a BP-80 homologue. This clone served as a probe for isolation of the BP- $80 \mathrm{cDNA}$ and three homologues from developing peas, and for another homologue from Arabidopsis. Database searches identified EST clones encoding homologues from rice and maize $[84,85]$. Other investigators independently identified members of the gene family comprising homologues to BP-80. Paul Dupree (University of Cambridge, UK) identified the Arabidopsis EST clone Z38123 from amino acid sequence data obtained from an abundant protein in purified Arabidopsis Golgi preparations (P. Dupree, personal communication). Ahmed et al. [1], using computer searches for motifs associated with epidermal growth factor (EGF) repeats found in animal receptors, also identified an Arabidopsis sequence indistinguishable from EST clone Z38123. Raphael Pont-Lezica's laboratory (Université Paul Sabatier, Toulouse, France), using a PCR-based approach to isolate proteins similar to animal integrins, also cloned from Arabidopsis a homologue of BP-80. The function of these proteins in Arabidopsis is being tested with antisense and sense overexpression transgenic plants (R. Pont-Lezica, personal communication). As noted above, Shimada et al. [100] identified 72 and $82 \mathrm{kDa}$ proteins from lysates of pumpkin dense vesicle preparations that bound to an affinity column carrying the proaleurain VSD peptide, and sequence data obtained from their cDNA clones demonstrated that they are homologues of pea BP-80.

We have termed this gene family the VSR (for probable vacuolar sorting receptor) family [85]. The predicted protein sequences of VSR proteins can be described from that of the prototype, BP-80 (or $\mathrm{VSR}_{p s-1}$; [85]): The protein contains 623 amino acids, of which the first 22 represent a signal peptide. A single 24 residue hydrophobic region, consistent with a transmembrane domain, is present within the mature polypeptide. This finding predicts that BP80 is a type I transmembrane protein with a large $\mathrm{N}$-terminal luminal domain, a single transmembrane domain, and a C-terminal cytoplasmic domain of 37 amino acids. This organization is consistent with predictions of protein structure made from protease treatment of CCVs [54]. Confirming our prediction of a single transmembrane domain, a truncated form of BP-80 lacking the predicted transmembrane domain and cytoplasmic tail was secreted when expressed in tobacco suspension culture protoplasts [85].

The VSR proteins represent a new gene family with the following novel characteristics [85]. The first ca. 400 amino acids represent a unique region without homologues in the yeast or mammalian gene databases. This unique region is followed by three Cys-rich EGF repeats, one of which is predicted to coordinate calcium ions. Then follows a short Ser- and Thr-rich sequence preceding the transmembrane domain. The cytoplasmic domain sequences are highly conserved for approximately the N-terminal $75 \%$ and then diverge. All, however, contain a form of the Tyr$\mathrm{X}-\mathrm{X}$ hydrophobic motif, YMPL; this motif has been demonstrated to mediate incorporation into $\mathrm{CCV}_{\mathrm{s}}$ in mammalian systems $[5,6,80,81]$. Thus it is likely that all of the members of the VSR family described to date traffic in CCVs. Consistent with this prediction, BP-80 is highly enriched in preparations of pea CCVs lacking detectable storage proteins, while pea smooth dense vesicle preparations are highly enriched in storage proteins but have little detectable BP-80 ([90]; Robinson, this volume).

\section{Traffic of BP-80 to Golgi and a lytic prevacuolar compartment}

We prepared antibodies to a synthetic peptide representing the N-terminal 20 amino acids of BP-80, and a monoclonal antibody that recognized BP-80 as well as, probably, other pea VSR proteins [85]. In immunofluorescence experiments with laser scanning confocal microscopy, the two antibodies co-localized to punctate and small spherical structures in pea root tip cells. Comparison with labeling patterns obtained with anti- $\alpha$-TIP and TIP-Ma27 antibodies demonstrated that neither type of vacuole tonoplast was labeled with the anti-BP-80 antibodies, but a network of small punctate organelles positive for BP-80 appeared to surround vacuoles labeled with TIP-Ma27. Immunogold electron microscopy using the anti-Nterminal BP-80 peptide antibodies demonstrated spe- 
cific labeling of Golgi and of what we termed prevacuoles [85]. These were ca. $250 \mathrm{~nm}$ vacuoles that were found in groups adjacent to large vacuoles, some of which appeared to be in the process of fusing with the large vacuoles. Thus the postulated receptor protein was demonstrated to be present in Golgi, where ligand binding could occur, and in small vacuoles capable of fusing with larger vacuoles where, presumably, an acidic $\mathrm{pH}$ environment and ligand release could occur. The confocal immunofluorescence results indicated that these large vacuoles were likely to be marked by TIP-Ma27 in their tonoplast and therefore were lytic vacuoles. This observation would be consistent with the finding that aleurain was exclusively present in vacuoles labeled by TIP-Ma27 antibodies [86]. A green fluorescent protein (GFP) sequence fused to the transmembrane and cytosolic domains of $\mathrm{VSR}_{p s-1}$ was expressed in protoplasts and transgenic plants where it labeled mostly Golgi-sized particles (N. Paris and J.-M. Neuhaus, unpublished observations).

In aggregate, these results are consistent with the model presented in Figure 1, where sorting of proteins with a sSVSD is mediated by a receptor, a member of the VSR protein family, that binds its ligand in the Golgi and delivers it to an acidified prevacuolar compartment. Golgi to prevacuole traffic is likely to occur in CCVs. This model is consistent with what is known of traffic of proteins to the vacuole in yeast. There, the Vps10p vacuolar sorting receptor $[16,61]$ binds its ligands in the Golgi and delivers them to an acidified prevacuolar compartment that contains active proteases [88, 114].

The plant VSR proteins and yeast Vps10p share no homology, however. We speculate that plants required a specialized receptor because of the complex pattern of protein sorting to different vacuoles that occurs in plant cells [86]. The observation that several different genes for VSR proteins are expressed in the same plant tissue, for example at least four in developing pea seeds, would be reasonably explained if each VSR protein had a slightly different ligand binding specificity. Then the different VSR proteins could together select a broader population of proteins for delivery to the lytic vacuole. Alternatively, it is possible the different VSR proteins are each expressed in a different cell type. As methods for expressing and purifying the different VSR proteins are developed it will be possible to compare their ligand binding specificities and address this question.

\section{The C-terminal (ct-VSD) vacuolar sorting determinants}

The presence of a C-terminal propeptide in the precursor of a vacuolar protein was often the first hint for a C-terminal vacuolar sorting determinant. The propeptides were identified by comparison of the mature protein with the polypeptide encoded by a cDNA clone, as in cereal lectins or some storage proteins, or by comparison of predicted sequences for related vacuolar and secreted proteins, as in several families of pathogenesis-related proteins. It is likely that many $\mathrm{C}$ terminal propeptides were not identified because only few C-termini of vacuolar proteins have actually been sequenced and processing of a few amino acids does not cause a big discrepancy between predicted and observed molecular weight. Comparison of related proteins may also lead to the erroneous identification of a propeptide in a vacuolar or secreted protein. As an example, chitinases of classes II and IV, which are both secreted, differ at their C-termini by six to nine amino acids [76]. Accordingly only a few C-terminal propeptides have been positively identified: in a barley lectin [22], in a chitinase, a glucanase and an osmotin from tobacco $[71,78,107]$ and in $2 S$ albumin storage proteins from Brazil nut [96] and pea [34].

Deletion from the precursor protein and fusion to several reporter proteins (cucumber chitinase, hen egg white lysozyme, rat $\beta$-glucuronidase, GFP) indicated that the C-terminal propeptide (GLLVDTM) of tobacco chitinase $\mathrm{A}$ is both necessary and sufficient for vacuolar targeting [78]. The sequence requirements for vacuolar sorting of chitinase A were characterized by deletion and mutation analysis [77]. In contrast to sequence-specific VSDs, no essential motif was found. Apart from the terminal Met, which was dispensable, all partial deletions strongly reduced the percentage of intracellular chitinase. Single and multiple replacements affected sorting to varying degrees. Random sequences also showed varying sorting efficiencies. The effects of multiple substitutions were often additive, but no general rule could be deduced from them: neither more hydrophilic, nor more hydrophobic residues were in all cases favored. Indeed, replacement of the three hydrophobic residues (-LLV-) by Ser (-SSS-) or of the terminal four mostly hydrophilic residues (-VDTM) by Leu (-LLLL) only poorly reduced the sorting efficiency. The single most effective replacement was unexpected: while deletion of the terminal Met or its replacement by Phe or Lys had little 
effect, its replacement by a Gly reduced the sorting efficiency by more than $50 \%$.

Partial deletions of the propeptide of barley lectin established that no single portion of its 15 amino acids is essential [22]. Instead, the first four or the last four residues each were sufficient. Furthermore, a minimal length of three (!) amino acids beyond the processing site was sufficient for significant vacuolar targeting. Four Ala were effective as were -LLVD or -PIRP but not four Glu or four Lys. The internal N-glycosylation site was dispensable [120]. There was however a way to destroy the function of the VSD by blocking its C-terminus. Replacement of two or more terminal residues from a truncated but still functional propeptide by Gly or even addition of two Gly to the end of the complete lectin propeptide caused secretion, apparently even more efficiently than complete deletion of the propeptide. A C-terminal N-glycosylation site (NATE) had the same effect. These results indicate that the VSD has to be accessible from its very C-terminus and that the terminal amino acid cannot be a glycine. Precedents for such C-terminally located sorting signals include the ER-retention signal (-K/HDEL) and the peroxisomal targeting signal PTS-1 (-SKL), which can also be inactivated by addition of amino acids.

The four amino acids long C-terminal propeptide of the $2 \mathrm{~S}$ albumin from Brazil nut was shown to be necessary for vacuolar targeting in transgenic tobacco [55]. It was however not sufficient for vacuolar targeting of invertase, which required a much longer C-terminal fragment from the $2 \mathrm{~S}$ albumin, including sequence preceding the last cysteine, which is highly conserved in related storage proteins and probably is involved in a disulfide bond. Furthermore it includes a potential glycosylation site; it is not known if this site is glycosylated in either the $2 \mathrm{~S}$ albumin or in the $2 \mathrm{~S}$ invertase fusion protein. It is thus not certain that the sequence acting as a VSD on invertase is really accessible in the wild-type protein. On the other hand, the binding experiments (discussed above) with proteins solubilized from a pea vesicle fraction indicated that the nine last residues of the $2 \mathrm{~S}$ albumin could bind a protein of $80 \mathrm{kDa}$ similar or identical to the putative sorting receptor for ss-VSDs, $\mathrm{VSR}_{p s-1}$ [85]. These nine residues all follow the last cysteine and may well contain a VSD overlapping the processing site. As a ssVSD the Ile at position -4 could be important. A ctVSD has also not yet been excluded, which could be done most easily by adding two Gly at the end, as has been done with the barley lectin [22]. Finally, wortmannin sensitivity might also give a clue as to which type of VSD is actually involved in targeting albumins in various plants (see below). In the related Arabidopsis $2 \mathrm{~S}$ albumin, deletion of the two amino acids long propeptide did not change the vacuolar targeting [19]. In this case, it is clear that the vacuolar targeting involves precipitation, which is the third type of sorting determinant discussed below.

Is there really no sequence specificity at all? Quantitative analysis of sorting efficiency indicated that there are differences depending on the sequence. Not every random sequence was indeed effective. There are precedents for a peptide recognition system without conserved motifs. There are no absolutely conserved sequences for either the ER-targeting signal peptides or for the transit peptides of mitochondrial or chloroplastic proteins. In the first two cases, random peptides were also tested and every third sequence was found to target the protein to the investigated compartment, a proportion similar to the one observed for vacuolar targeting of the tobacco chitinase.

A more precise model for the preferences of a sorting system with no conserved motif can be obtained by compiling the sequences of as many examples as possible from natural proteins, an approach that was successful for ER-targeting signal sequences and mitochondrial transit peptides [117]. For C-terminal VSDs it is severely limited by the small number of protein families were such a propeptide has been identified. It is thus only possible to compare sequences of cereal lectins and of pathogenesis-related proteins. Such a comparison reveals certain constants: the preferred terminal residue is Met (chitinases from tobacco, tomato, poplar, elm tree, cotton; glucanases from tobacco, potato, hevea, alfalfa and pea), or else Leu, Ile or Val (chitinases from Arabidopsis, potato, grapevine, Vigna; glucanase from tomato, bean; PR-4 from Arabidopsis; PR-1 from tobacco; lectin from rice). Amino acids with a long aliphatic chain are accepted even if they carry a terminal charge: Glu (barley and wheat lectins; thaumatin; PR-4 from tobacco, potato, tomato, hevea) or Lys (osmotins from potato and tomato). At position $-2,-3$ or -4 , there is a preference for negatively charged or hydrophilic neutral. Typical ct-VSD end with -DTM or -SEM or -EVA(K). There may be different preferences in different species. For example, both chitinase and glucanase from bean have a frameshift within the coding sequence of the VSD that causes a divergence from the consensus mentioned above. Both chitinases and lectins from cereals end with $-\mathrm{AE}(\mathrm{A})$. The putative receptor is proposed to interact with the terminal carboxyl group and with the 
backbone of the few last amino acids of the VSD rather than with the side chains. At the C-terminus there must be a hydrophobic patch requiring at least one methyl group but preferably one or several methylene groups, while the terminal functional group is of little importance. Such binding domains have been described in animal proteins.

A low sequence specificity for a short peptide would predict a low binding affinity for a receptor protein. This may explain why several attempts to identify a receptor have failed so far (screening of an expression library with a labeled peptide, anti-idiotypic antibodies, affinity column). Would low-affinity binding be functionally acceptable for a vacuolar sorting system? The proteins with ctVSDs are not digestive enzymes like the proteases with ssVSDs. In the case of the pathogenesis-related proteins, there even are secreted isoforms. If some leakiness is tolerated, a low affinity may be sufficient to partition most proteins to the membrane in the conditions of high surface to volume ratio in the Golgi apparatus. It should also be noted that, contrary to ssVSDS, ctVSDs can be very easily acquired or lost by point mutations or small insertions or deletions without affecting the proper folding of the protein.

An alternative possible explanation for a mechanism by which a ctVSD might function should, however, be kept in mind. The C-terminus of a protein may have important effects on the final three dimensional structure of the molecule. 'For many proteins, the Cterminal segment of 20-30 amino acid residues, which is sheltered by the ribosome prior to the release of the full length polypeptide into the bulk solution, is essential for formation of the native, biologically active structure' [23]. The final step in folding may involve binding of the C-terminus to the surface of the folded core (reviewed in [23]). If the three-dimensional structure of proteins is a determinant for sorting them into vesicles in the PSV pathway (see below), removal of a C-terminal propeptide could substantially affect that determinant. Additionally, the limited sequence requirements described above would also be consistent with charge and/or hydrophobicity constraints on precise interaction between the external C-terminus and a properly folded internal core. This mechanism is however difficult to reconcile with very short ctVSDs such as those of chitinases.

\section{The physical structure (ps-VSD) vacuolar sorting determinants}

There is a third heterogeneous group of proteins for which neither of the two first categories of VSD seem to apply. They are known or supposed not to have propeptides, or if propeptides are present, they have been shown not to be required for vacuolar sorting. The sorting determinant must somehow be carried within the mature polypeptide. An internal ssVSD is possible, but for several seed storage proteins, another sorting system is likely to be involved. These are the vicilin-like and legumin-like proteins that accumulate into dense vesicles at the trans side of the Golgi and are transported without involvement of clathrin coated vesicles [38, 39, 90]. (Recent studies in developing pea cotyledons $[38,39,90]$ and in pumpkin cotyledons [100] have identified structures that are likely to represent a PSV prevacuolar compartment to which the dense vesicles traffic from the Golgi.) The seed storage proteins accumulate in protein storage vacuoles distinct from the lytic vacuoles that preexisted in these cells. Early studies of the transport to vacuoles were mostly performed with these proteins. They established several important facts such as the synthesis in the ER, glycan modifications in the Golgi [13] and accumulation in seed protein bodies $[35,108]$ as well as in leaf vacuoles of heterologous species [42, 101]. Glycosylation was found to be irrelevant for the final localization, excluding a mammalian type of sorting system based on glycan side chains [9, 102]. Even though phytohemagglutinin (PHA) was one of the first plant vacuolar proteins analysed in this respect it is still unclear where its sorting determinants reside. The sorting determinants for PHA were first studied by fusion of truncated PHA with invertase and expression in yeast $[110,111]$, but it was recognized later that yeast and plants probably utilize different sorting determinants. The determinants were tentatively localized within a surface loop [118], but, because the results were obtained by fusion of truncated PHA with invertase, concerns about possible misfolding of the chimeric reporter protein would need to be addressed. The role of the C-terminal propeptide of PHA also requires further study, as it resembles the ctVSDs described above [122]. The theoretical role of a Cterminal propeptide in affecting folding and therefore presentation of hydrophobic patches has been discussed above and may be relevant for the following alternative model. 
A targeting study with legumin indicated the spread of sorting information over several sequence elements, suggesting an important role for higher structures [96]. Comparison of several vacuolar proteins also tentatively identified surface determinants contributed by non-contiguous sequences as possible sorting determinants [99]. As discussed by Vitale and Chrispeels [116], aggregation is a possible sorting mechanism. Sorting by aggregation is known to occur in animal cells, where it is possibly due to a lowered $\mathrm{pH}$ [reviewed in 12]. An extreme form of aggregation is presented by cereal prolamins which aggregate within the ER to form protein bodies [reviewed in 83]). Deposition of other storage proteins into protein bodies may occur in PSV after transit through the Golgi. This will be discussed in another review in this volume (Müntz, this volume). Determinants for aggregation would likely be associated with hydrophobic regions on the surface of the molecule formed by folding of the three dimensional protein structure. In this regard, it is interesting that the precursor to the pea storage protein legumin, prolegumin, isolated from ER and Golgi vesicles, is much more hydrophobic and binds much more tightly to membranes than the mature legumin protein [40]. If such surface patches exist, they would be much more difficult to localize than VSDs present on propeptides.

\section{Biochemical evidence for two functionally distinct sorting pathways}

As discussed at the beginning of this review, there clearly are (at least) two types of vacuoles in root tip cells, with one being the compartment of ssVSDtargeted proteins such as aleurain, while the other compartment is the destination of ctVSD-targeted proteins such as barley lectin [86]. In developing pea cotyledons it is also clearly possible to distinguish storage vacuoles from lytic vacuoles as well as the corresponding dense vesicles and clathrin-coated vesicles [90]. In mature plant tissue, however, barley lectin and sporamin are found together in aggregates in the central vacuole [97]. This finding indicates that pathways for sorting proteins with the two types of VSD may ultimately converge on the central vacuole, but the sensitivity of the method used in that study probably would not have allowed detection of the individual proteins in other intermediate compartments [86].

Matsuoka et al. [68] developed a system in tobacco suspension culture cells to test the effects of com- pounds known to affect sorting processes in yeast and mammalian cells. Two reporter proteins were used: prosporamin or sporamin lacking its prosequence to which the barley lectin C-terminal propeptide was attached, and probarley lectin or barley lectin lacking its prosequence to which the $\mathrm{N}$-terminal prosporamin propeptide was attached. Thus, the functions of the prosporamin ssVSD and barley lectin ctVSD were tested separately on two different proteins. While both sporamin and barley lectin lacking any propeptide sequences were secreted from the cells, either propeptide caused the reporter proteins to be efficiently sorted to the vacuole. Wortmannin, an inhibitor of phosphatidylinositol 3-kinase in mammalian cells and of synthesis of phospholipid and phosphatidylinositol 4phosphate in plant cells, caused almost complete inhibition of ctVSD-mediated transport to the vacuole at a concentration, $33 \mu \mathrm{M}$, that had little or no effect on ssVSD-mediated trasport to the vacuole [68]. Wortmannin also inhibited vacuolar sorting of the endogenous tobacco chitinase, as well as the sorting of fusion proteins carrying its VSD, such as rat $\beta$-glucuronidase and (Di Sansebastiano, Paris and Neuhaus, unpublished observation). There are no reports yet on its effects on sorting of proteins with a psVSD.

The results from experiments using wortmannin emphasize that two separate pathways to a vacuole may function within the same cell. Do two separate pathways to two separate vacuoles function simultaneously within the same cell? Evidence from studies of developing pea cotyledons indicate that this may be true. Both CCVs and dense vesicles have been purified from developing pea cotyledons, where dense vesicles traffic to PSV and contain storage proteins but no BP-80, while CCVs traffic to LV and contain BP80 but no storage proteins (Robinson, this volume). Additionally, when the GFP was fused with the ctVSD of chitinase and expressed in tobacco protoplasts, its localisation was, as expected, vacuolar in most mesophyll protoplasts. However, in chloroplast-poor protoplasts, it was mostly concentrated in a smaller compartment, while the large vacuole remained nonfluorescent. Some protoplasts of this type were also found to have a large green vacuole. When the protoplasts were stained with Neutral Red, a dye trapped in acidic compartments in the protonated form [73], we found that the GFP-positive vacuoles did not accumulate Neutral Red, while the GFP-negative vacuoles turned red. It is thus possible to stain differentially two types of vacuoles in leaf-derived protoplasts (Di Sansebastiano, Paris and Neuhaus, submitted). 
Are there two or three types of vacuoles? There is a lack of information on the respective localisation of proteins targeted by ctVSDs and psVSDs, while each category has been compared with the proteins with a ssVSD. Thus, we know that the latter proteins are transported by CCVs in a wortmannininsensitive manner, but we don't know yet whether the wortmannin-sensitive pathway (ctVSDs) is the pathway involving smooth dense vesicles (psVSDs).

\section{Sorting of one protein to both PSV and LV compartments}

The barley aspartic proteinase [95] is present in both PSVs and LVs [86]. Two potential VSDs are present in the proenzyme sequence. The sequence NPLR is found in the N-terminal propeptide, a motif that functions as well as NPIR when placed in the prosporamin ssVSD [59]. Additionally, in comparison to yeast and mammalian aspartic proteinases, the barley enzyme and other plant homologues have a central insert of 104 amino acids that closely resembles the sequence of mammalian saposins [28]. Saposins interact with certain lysosomal enzymes and are thought to be involved with the membrane-associated mannose-6phosphate-independent pathway for targeting proteins to lysosomes [103, 123]. Interestingly, direct evidence that this 'saposin' insert in the barley aspartic proteinase participates in vacuolar sorting comes from expression experiments in tobacco suspension culture cells. While the intact proenzyme was efficiently targeted to the vacuole, a mutated form with an intact $\mathrm{N}$-terminal propeptide, but where the 'saposin' insert had been deleted, was secreted from the cells [112].

The topological distribution of different sorting mechanisms within the Golgi may be important in determining how a protein with two possible VSDs is sorted. For some proteins, a process of aggregation appears to be underway in the cis-Golgi as judged from electron micrographs showing protein inclusions in the dilated ends of Golgi cisternae, where the electron opacity of the inclusions appears to increase in a cis-to-trans gradient. The opacity of the trans-most aggregates matches those of contents of smooth dense vesicles which appear to bud off of medial- and transGolgi $[56,90]$. If receptor-mediated sorting is localized predominantly in the trans-Golgi, a fact not yet established in plants, proteins with potential ssVSDs that participate in an intra-Golgi aggregation process would have little opportunity to reach a location where that sorting mechanism is active.
A same propeptide may function with two sorting systems. This was found with the propeptide of sporamin, when it was moved to a C-terminal position [59]. In contrast to results obtained with an $\mathrm{N}$-terminal ssVSD, mutation of the Ile to Gly had little effect on vacuolar sorting when the ssVSD was at the C-terminus. When the effects of wortmannin were tested, again it had no effect on vacuolar sorting when the unmutated ssVSD was used, but strongly inhibited vacuolar transport when the Ile $\rightarrow$ Gly mutation was present. Thus the Ile $\rightarrow$ Gly mutation appeared to acquire, or revealed, functional characteristics of a ctVSD in this sequence when placed at the C-terminus of that protein; this result emphasizes the apparent position-specific requirement for function of the ctVSD, in contrast to function of the ssVSD.

The ER retention signal can also mediate vacuolar sorting. When sporamin carrying an HDEL extension was expressed in tobacco BY2 cells, a significant fraction escaped the ER and was recovered in the vacuole [26]. This is not surprising when the resemblance of HDEL with the rules for ctVSDs is considered. Function of HDEL as a ctVSD would enable plant cells to send ER proteins to a vacuole if they escaped the retrieval system or as a means to change the localization during development. The latter would potentially apply for the plant cysteine endopeptidase containing a KDEL sequence that degrades seed globulins in protein bodies after germination [82]. This might be one way to transform a storage vacuole into a digestive vacuole.

\section{Transport of cytoplasmic proteins into the vacuole}

In yeast, certain proteins synthesized on free ribosomes in the cytoplasm are transported directly into the vacuole without entering the secretory pathway $[57,98]$, and this process utilizes some mechanisms in common with autophagy [2]. Several plant proteins that are likely to reach the vacuole by a similar process have been identified. Prominent among these is a soybean lipoxygenase that accumulates in paraveinal mesophyll cell vacuoles as a vegetative storage protein $[10,113]$, as well as certain late embryogenesis-abundant proteins [24, 63].

\section{Sorting of integral membrane proteins to vacuoles}

As noted above, transport of integral membrane proteins to the appropriate tonoplast may involve 
processes similar to those used for vacuolar biogenesis. TIPs are difficult to detect in either CCVs or purified dense vesicles from developing peas (Robinson, this volume), so it is likely that their transport in large quantities to PSV or LV tonoplast must involve other pathways. Studies of transgenic tobacco plants expressing $\alpha$-TIP have provided some insights into this question. Höfte et al. [42] demonstrated that, in such plants, $\alpha$-TIP was transported to the leaf central vacuole tonoplast, where dense labeling with anti- $\alpha$ TIP antibodies was observed by electron microscopic immunocytochemistry. A chimeric protein consisting of the phosphinotricine acetyltransferase sequence attached to the C-terminal transmembrane domain and cytoplasmic tail of $\alpha$-TIP similarly was transported to the tonoplast in transgenic tobacco cells, as was a small amount of a truncated form from which the 15 C-terminal amino acids had been deleted [41]. The latter results indicated that at least the $\mathrm{C}$-terminal transmembrane domain plus a portion of the cytoplasmic tail had sufficient information to cause them to be directed to tonoplast.

If $\alpha$-TIP is a specific marker for PSVs, why should it be efficiently transported to the central vacuole tonoplast? First, it is not clear that the $\alpha$-TIP protein did not pass through a small PSV equivalent in the cells before ending up in the central vacuole. Such a compartment might require detailed studies to be detected by electron microscopy, and the floatation method used to isolate vacuoles in those studies might permit co-isolation of central vacuoles and small vacuoles representing other compartments. Second, it is clear that in some pea and barley root tip cells, vacuoles are present where both $\alpha$-TIP and TIP-Ma27 co-localize in the tonoplast [86], and similar results have been obtained using anti-peptide antibodies that are specific for $\alpha$-TIP and $\gamma$-TIP (G.-Y. Jauh and J.C. Rogers, unpublished data). We have hypothesized that this may occur as a cell makes a decision no longer to store proteins in PSVs [86]. It is likely that a cell wanting to establish and maintain separate PSVs and LVs would have to express not only the specific TIPs but also numerous other proteins that would be responsible for preventing fusion of the two types of tonoplast as they were synthesized, and it is unlikely that these other proteins would have been expressed in the transgenic tobacco cells that were studied [41, 42].

Interestingly, transport of $\alpha$-TIP to the tonoplast in transgenic tobacco cells was not prevented by treatment with brefeldin $\mathrm{A}$, under conditions where that drug completely prevented sorting of the storage pro- tein phytohemagglutinin to the vacuole in the same cells [25]. As brefeldin A exerts major effects by abolishing forward movement from ER to Golgi [30, 105], this finding indicates that $\alpha$-TIP may follow a path directly from ER to tonoplast without passing through the Golgi. The ability of the C-terminal cytoplasmic tail of $\alpha$-TIP to prevent movement from ER to Golgi has been documented in another system [52]. A chimeric protein consisting of a mutated form of proaleurain lacking a functional ssVSD was fused to the transmembrane domain and cytoplasmic tail of the VSR protein BP-80. When expressed in tobacco suspension culture protoplasts, the BP-80 transmembrane domain/cytoplasmic tail directed the reporter to the lytic prevacuole where the proaleurain moiety was processed to mature form. Substitution of the $\alpha$-TIP C-terminal cytoplasmic tail, or the C-terminal transmembrane domain plus cytoplasmic tail, for the corresponding BP-80 sequences prevented both transit through the Golgi and traffic to the site of proaleurain processing [52]. Thus, the $\alpha$-TIP cytoplasmic tail may be recognized by cytoplasmic proteins that act to exclude the protein from vesicles trafficking from ER to Golgi, and possibly may direct it into a pathway leading to tonoplast. It will be of considerable interest to characterize further the molecular mechanisms and pathways used by different TIPs to reach their tonoplast destinations.

\section{The plant vacuolar system}

The complexity of what reasonably can be considered a vacuolar system in plant cells, a system of separate but interacting organelles not found in yeast and animal cells, offers a rich field of future work for plant cell biologists. Initial progress is likely to depend upon biochemical approaches using plant cells, because molecular genetics approaches using precedents from yeast or animal systems may be difficult to interpret. For example, plant homologues of yeast proteins involved in traffic to the vacuole cannot necessarily be assumed to participate exclusively in Golgi to LV traffic. The plant system is likely to provide new insights into organelle biogenesis and protein traffic that will be a substantial contribution to the general field of cell biology. Several examples can be offered. The mechanisms of sorting proteins into the dense vesicle pathway leading to PSVs, and the molecular composition of dense vesicle membranes and coat proteins should provide novel information. The 
plant VSR proteins are without yeast or animal homologues, and their ligand binding preferences and three dimensional molecular structure will be of considerable interest. The mechanisms by which plant cells make and maintain separate types of vacuoles, and the mechanisms and reasons for merger of different vacuole types should contribute fundamental knowledge of processes involved in regulating 'homotypic fusion' [79]. We look forward with excitement to the next decade in plant cell biology.

\section{Acknowledgements}

The authors thank Nadine Paris for useful discussions. This work was supported by the Swiss National Science Foundation, grant 31-46926.96 to J.-M. N., and grants from the Department of Energy and National Institutes of Health to J.C.R.

\section{References}

1. Ahmed SU, Bar-Peled M, Raikhel NV: Cloning and subcellular location of an Arabidopsis receptor-like protein that shares common features with protein-sorting receptors of eukaryotic cells. Plant Physiol 115: 311-312 (1997).

2. Baba M, Osumi M, Scott SV, Klionsky DJ, Ohsumi Y: Two distinct pathways for targeting proteins from the cytoplasm to the vacuole/lysosome. J Cell Biol 139: 1687-1695 (1997).

3. Balch WE, McCaffery JM, Plutner H, Farquhar MG: Vesicular stomatitis virus glycoprotein is sorted and concentrated during export from the endoplasmic reticulum. Cell 76 : 841-852 (1994)

4. Barlow KK, Lee JW, Vesk M: Morphological development of storage protein bodies in wheat. In: Bieleski RL, Freguson AR, Cresswell MM (eds) CSIRO Mechanisms of Regulation of Plant Growth, pp. 793-797. Royal Society of New Zealand, Wellington (1974).

5. Boll W, Gallusser A, Kirchhausen T: Role of the regulatory domain of the EGF-receptor cytoplasmic tail in selective binding of the clathrin-associated complex AP-2. Curr Biol 5: 1168-1178 (1995).

6. Boll W, Ohno H, Zhou SY, Rapoport I, Cantley LC, Bonifacino JS, Kirchhausen T: Sequence requirements for the recognition of tyrosine-based endocytic signals by clathrin AP-2 complexes. EMBO J 15: 5789-5795 (1996).

7. Boller T, Kende H: Hydrolytic enzymes in the central vacoule of plant cells. Plant Physiol 63: 1123-1132 (1979).

8. Boller T, Wiemken A: Dynamics of vacuolar compartmentation. Annu Rev Plant Physiol 37: 137-164 (1986).

9. Bollini R, Ceriotti A, Daminati MG, Vitale A: Glycosylation is not needed for the intracellular transport of phytohemagglutinin in developing Phaseolus vulgaris cotyledons and for the maintenance of its biological activities. Physiol Plant 65 : 15-22 (1985).

10. Bunker TW, Loetje DS, Stephenson LC, Creelman RA, Mullet JE, Grimes HD: Sink limitation induces the expression of multiple soybean vegetative lipoxygenase mRNAs while the endogenous jasmonic acid level remains low. Plant Cell 7: 1319-1331 (1995)

11. Burgess J, Lawrence W: Studies of the recovery of tobacco mesophyll protoplasts from an evacuolation treatment. Protoplasma 126: 140-146 (1985).

12. Castle AM, Huang AY, Castle JD: Passive sorting in maturing granules of AtT-20 cells: the entry and exit of salivary amylase and proline-rich protein. J Cell Biol 138: 45-54 (1997).

13. Chrispeels MJ: The golgi apparatus mediates the transport of phytohemagglutinin to the protein bodies in bean cotyledons. Planta 158: 140-151 (1983).

14. Chrispeels MJ, Maurel C: Aquaporins: the molecular basis of facilitated water movement through living plant cells? Plant Physiol 105: 9-13 (1994).

15. Chrispeels MJ, Raikhel NV: Short peptide domains target proteins to plant vacuoles. Cell 68: 613-616 (1992).

16. Cooper AA, Stevens TH: Vps10p cycles between the lateGolgi and prevacuolar compartments in its function as the sorting receptor for multiple yeast vacuolar hydrolases. J Cell Biol 133: 529-541 (1996).

17. Craig S, Goodchild DJ, Miller C: Structural aspects of protein accumulation in developing pea cotyledons. II. Threedimensional reconstructions of vacuoles and protein bodies from serial sections. Aust J Plant Physiol 7: 329-337 (1980).

18. Culianez-Macia FA, Martin C: DIP: a member of the MIP family of membrane proteins that is expressed in mature seeds and dark-grown seedlings of Antirrhinum majus. Plant J 4: 717-725 (1993).

19. D'Hondt K, Van Damme J, Van Den Bossche C, Leejeerajumnean S, De Rycke R, Derksen J, Vandekerckhove J, Krebbers E: Studies of the role of the propeptides of the Arabidopsis thaliana 2S albumin. Plant Physiol 102: 425-433 (1993).

20. Dahms NM, Wick DA, Brzycki-Wessell MA: The bovine mannose 6-phosphate/insulin-like growth factor-II receptor Localization of the insulin-like growth factor-II binding site to domains 5-11. J Biol Chem 269: 3802-3809 (1994)

21. Denecke J, Botterman J, Deblaere R: Protein secretion in plant cells can occur via a default pathway. Plant Cell 2: 51-59 (1990).

22. Dombrowski JE, Schroeder MR, Bednarek SY, Raikhel NV Determination of the functional elements within the vacuolar targeting signal of barley lectin. Plant Cell 5: 587-596 (1993).

23. Fedorov AN, Baldwin TO: Cotranslational protein folding. $\mathrm{J}$ Biol Chem 272: 32715-32718 (1997).

24. Franz G, Hatzopoulos P, Jones TJ, Krauss M, Sung ZR: Molecular and genetic analysis of an embryonic gene, DC8, from Daucus carota L. Mol Gen Genet 218: 143-151 (1989).

25. Gomez L, Chrispeels MJ: Tonoplast and soluble vacuolar proteins are targeted by different mechanisms. Plant Cell 5: 1113-1124 (1993).

26. Gomord V, Denmat LA, Fitchette-Lainé AC, SatiatJeunemaitre B, Hawes C, Faye L: The C-terminal HDEL sequence is sufficient for retention of secretory proteins in the endoplasmic reticulum (ER) but promotes vacuolar targeting of proteins that escape the ER. Plant 11: 313-325 (1997).

27. Greenwood JS, Stinissen HM, Peumans WJ, Chrispeels MJ: Sambucus nigra agglutinin is located in protein bodies in the phloem parenchyma of the bark. Planta 167: 275-278 (1986).

28. Guruprasad K, Törmäkangas K, Kervinen J, Blundell TL: Comparative modelling of barley-grain aspartic proteinase: a 
structural rationale for observed hydrolytic specificity. FEBS Lett 352: 131-136 (1994)

29. Harley SM, Beevers L: Coated vesicles are involved in the transport of storage proteins during seed development in Pisum sativum L. Plant Physiol 91: 674-678 (1989).

30. Hawes C, Satiat-Jeunemaitre B: Stacks of questions: how does the plant Golgi work? Trends Plant Sci 1: 395-401 (1996).

31. Herman EM: Multiple origins of intravacuolar protein accumulation of plant cells. In Malhotra S (ed), Advances in Structural Biology, pp. 243-283. JAI Press, Greenwich, CT (1994).

32. Herman EM, Hankins CN, Shannon LM: Bark and leaf lectins of Sophora japonica are sequenstered in proteinstorage vacuoles. Plant Physiol 86: 1027-1031 (1987).

33. Herman EM, Lamb CJ: Arabinogalactan-rich glycoproteins are localized on the cell surface and in intravacuolar multivesicular bodies. Plant Physiol 98: 264-272 (1992).

34. Higgins TJV, Chandler PM, Randall PJ, Spencer D, Beach LR, Blagrove RJ, Kortt AA, Inglis AS: Gene structure, protein structure, and regulation of the synthesis of a sulfur-rich protein in pea seeds. J Biol Chem 261: 11124-11130 (1986).

35. Higgins TJV, Newbigin EJ, Spencer EJ, Llewellyn DJ, Craig $\mathrm{S}$ : The sequence of a pea vicilin gene and its expression in transgenic tobacco plants. Plant Mol Biol 11: 683-695 (1989).

36. Higuchi T, Hisada H, Morishima S, Okada Y, Maeshima M: Molecular cloning, water channel activity and tissue specific expression of two isoforms of radish vacuolar aquaporin. Plant Cell Physiol, in press (1998)

37. Hilling B, Amelunxen F: On the development of the vacuole. II. Further evidence for endoplasmic reticulum origin. Eur J Cell Biol 38: 195-200 (1985).

38. Hinz G, Bäumer M, Hohl I, Hillmer S, Robinson DG: Identification and characterization of a post-Golgi, prevacuolar compartment involved in storage protein transport in pea cotyledon cells. J Cell Sci, in press (1998).

39. Hinz G, Hillmer S, Bäumer M, Hohl I: Vacuolar storage proteins and the putative vacuolar sorting receptor BP-80 are sorted into different transport vesicles in the Golgi apparatus of developing pea. Plant Cell 10, in press (1998).

40. Hinz G, Menze A, Hohl I, Vaux D: Isolation of prolegumin from developing pea seeds: its binding to endomembranes and assembly into prolegumin hexamers in the protein storage vacuole. J Exp Bot 48: 139-149 (1997).

41. Höfte H, Chrispeels MJ: Protein sorting to the vacuolar membrane. Plant Cell 4: 995-1004 (1992).

42. Höfte H, Faye L, Dickinson C, Herman EM, Chrispeels MJ: The protein body proteins phytohemagglutinin and tonoplast intrinsic protein are targeted to vacuoles in leaves of transgenic tobacco. Planta 184: 431-437 (1991).

43. Höfte H, Hubbard L, Reizer J, Ludevid D, Herman EM, Chrispeels MJ: Vegetative and seed-specific forms of tonoplast intrinsic protein in the vacuolar membrane of Arabidopsis thaliana. Plant Physiol 99: 561-570 (1992).

44. Hoh B, Hinz G, Jeong B-K, Robinson DG: Protein storage vacuoles form de novo during pea cotyledon development. J Cell Sci 108: 299-310 (1995).

45. Holwerda BC, Galvin NJ, Baranski TJ, Rogers JC: In vitro processing of aleurain, a barley vacuolar thiol protease. Plant Cell 2: 1091-1106 (1990).

46. Holwerda BC, Padgett HS, Rogers JC: Proaleurain vacuolar targeting is mediated by short contiguous peptide interactions. Plant Cell 4: 307-318 (1992).
47. Holwerda BC, Rogers JC: Purification and characterization of aleurain: a plant thiol protease functionally homologous to mammalian cathepsin H. Plant Physiol 99: 848-855 (1992).

48. Holwerda BC, Rogers JC: Structure, functional properties and vacuolar targeting of the barley thiol protease, aleurain. J Exp Bot 44 (Suppl): 321-339 (1993).

49. Hong E, Davidson AR, Kaiser CA: A pathway for targeting soluble misfolded proteins to the yeast vacuole. J Cell Biol 135: 623-633 (1996).

50. Inoue K, Wada Y, Nishimura M, Hara-Nishimura I: Heterologous expression and subcellular localization of pumpkin seed tonoplast intrinsic proteins (TIP) in yeast cells. Plant Cell Physiol 38: 366-370 (1997).

51. Ishikawa A, Ohta S, Matsuoka K, Hattori T, Nakamura K: A family of potato genes that encode Kunitz-type proteinase inhibitors: structural comparisons and differential expression. Plant Cell Physiol 35: 303-312 (1994).

52. Jiang L, Rogers JC: Golgi to prevacuole-targeting mechanisms of a plant vacuolar sorting receptor. Plant Physiol 114 (Suppl): 70 (1997).

53. Johnson KD, Herman EM, Chrispeels MJ: An abundant, highly conserved tonoplast protein in seeds. Plant Physiol 91: 1006-1013 (1989).

54. Kirsch T, Paris N, Butler JM, Beevers L, Rogers JC: Purification and initial characterization of a potential plant vacuolar targeting receptor. Proc Natl Acad Sci USA 91: 3403-3407 (1994)

55. Kirsch T, Saalbach G, Raikhel NV, Beevers L: Interaction of a potential vacuolar targeting receptor with amino- and carboxyl-terminal targeting determinants. Plant Physiol 111: 469-474 (1996)

56. Klauer SF, Franceschi VR: Mechanism of transport of vegetative storage proteins to the vacuole of the paraveinal mesophyll of soybean leaf. Protoplasma, in press (1997).

57. Klionsky DJ, Cueva R, Yaver DS: Aminopeptidase I of Saccharomyces cerevisiae is localized to the vacuole independent of the secretory pathway. J Cell Biol 119: 287-299 (1992).

58. Klionsky DJ, Herman PK, Emr SD: The fungal vacuole: composition, function and biogenesis. Microbiol Rev 54: 266-292 (1990).

59. Koide Y, Hirano H, Matsuoka K, Nakamura K: The Nterminal propeptide of the precursor to sporamion acts as a vacuole-targeting signal even at the $\mathrm{C}$ terminus of the mature part in tobacco cells. Plant Physiol 114: 863-870 (1997).

60. Maeshima M, Sasaki T, Asahi T: Characterization of major proteins in sweet potato tuberous roots. Phytochemistry 24: 1899-1902 (1985).

61. Marcusson EG, Horazdovsky BF, Cereghino JL, Gharakhanian E, Emr SD: The sorting receptor for yeast vacuolar carboxypeptidase $\mathrm{Y}$ is encoded by VPS10 gene. Cell 77: 579-586 (1994).

62. Marrs KA, Alfenito MR, Lloyd AM, Walbot V: A glutathione $S$-transferase involved in vacuolar transfer encoded by the maize Bronze-2. Nature 375: 397-400 (1995).

63. Marttila S, Tenhola T, Mikkonen A: A barley (Hordeum vulgare L.) LEA3 protein, HVA1, is abundant in protein storage vacuoles. Planta 199: 602-611 (1996).

64. Marty F: Cytochemical studies on GERL, provacuoles, and vacuoles in root meristematic cells of Euphorbia. Proc Natl Acad Sci USA 75: 852-856 (1978).

65. Marty F, Branton D, Leigh RA: Plant vacuoles. In: Tolbert NE (eds) The Biochemistry of Plants. Volume I. The Plant Cell, pp. 625-658. Academic Press, New York (1980). 
66. Marty-Mazars D, Clémencet M-C, Cozolme P, Marty F: Antibodies to the tonoplast from the storage parenchyma cells of beetroot recognize a major intrinsic protein related to TIPs. Eur J Cell Biol 66: 106-118 (1995).

67. Matile P: Biochemistry and function of vacuoles. Annu Rev Plant Physiol 29: 193-213 (1975).

68. Matsuoka K, Bassham DC, Raikhel N, Nakamura K: Different sensitivity to wortmannin of two vacuolar sorting signals indicates the presence of distinct sorting machineries in tobacco cells. J Cell Biol 130: 1307-1318 (1995).

69. Matsuoka K, Matsumoto S, Hattori T, Machida Y, Nakamura $\mathrm{K}$ : Vacuolar targeting and posttranslational processing of the precursor to the sweet potato tuberous root storage protein in heterologous plant cells. J Biol Chem 265: 19750-19757 (1990).

70. Matsuoka K, Nakamura K: Propeptide of a precursor to a plant vacuolar protein required for vacuolar targetting. Proc Natl Acad Sci USA 88: 834-838 (1991).

71. Melchers LS, Sela-Buurlage MB, Vloeans SA, Woloshuk CP, van Roekel JSC, Pen J, van den Elzen PJM, Cornelissen BJC: Extracellular targeting of the vacuolar proteins AP24, chitinase, and $\beta-1,3-$ glucanase in transgenic plants. Plant $\mathrm{Mol}$ Biol 21: 583-593 (1993).

72. Mizuno M, Singer SJ: A soluble secretory protein is first concentrated in the endoplasmic reticulum before transfer to the Golgi apparatus. Proc Natl Acad Sci USA 90: 5732-5736 (1993).

73. Moriyasu Y, Ohsumi Y: Autophagy in tobacco suspensioncultured cells in response to sucrose starvation. Plant Physiol 111: 1233-1241 (1996)

74. Nakamura K, Matsuoka K: Protein targeting to the vacuole in plant cells. Plant Physiol 101: 1-6 (1993).

75. Nakamura $\mathrm{K}$, Matsuoka $\mathrm{K}$, Mukumoto $\mathrm{F}$, Watanabe $\mathrm{N}$ : Processing and transport to the vacuole of a precursor to sweet potato sporamin in transformed tobacco cell line BY-2. J Exp Bot 44 (Suppl): 331-338 (1993).

76. Neuhaus J-M, Fritig B, Linthorst HJM, Meins F, Jr., Mikkelsen JD, Ryals J: A revised nomenclature for chitinase genes. Plant Mol Biol Rep 14: 102-104 (1996).

77. Neuhaus J-M, Pietrzak M, Boller T: Mutation analysis of the C-terminal vacuolar targeting peptide of tobacco chitinase: low specificity of the sorting system, and gradual transition between intracellular retention and secretion into the extracellular space. Plant J 5: 45-54 (1994).

78. Neuhaus J-M, Sticher L, Meins F, Boller T: A short Cterminal sequence is necessary and sufficient for the targeting of chitinases to the plant vacuole. Proc Natl Acad Sci USA 88: 10362-10366 (1991).

79. Nichols BJ, Ungermann C, Pelham HRB, Wickner WT, Haas A: Homotypic vacuolar fusion mediated by $\mathrm{t}$ - and $\mathrm{v}$-snares. Nature 387: 199-202 (1997).

80. Ohno H, Fournier MC, Poy G, Bonifacino JS: Structural determinants of interaction of tyrosine-based sorting signals with the adaptor medium chains. J Biol Chem 271: 29009-29015 (1996).

81. Ohno H, Stewart J, Fournier M-C, Bosshart H, Rhee I, Miyatake S, Saito T, Gallusser A, Kirchhausen T, Bonifacino JS: Interaction of tyrosine-based sorting signals with clathrin-associated proteins. Science 269: 1872-1875 (1995).

82. Okamoto T, Nakayama H, Seta K, Isobe T, Minamikawa T: Posttranslational processing of a carboxy-terminal propeptide containing a KDEL sequence of plant vacuolar cysteine endopeptidase (SH-EP). FEBS Lett 351: 31-34 (1994).
83. Okita TW, Rogers JC: Compartmentation of proteins in the endomembrane system of plant cells. Annu Rev Plant Physiol Plant Mol Biol 47: 327-350 (1996).

84. Paris N, Rogers JC: The role of receptors in targeting soluble proteins from the secretory pathway to the vacuole. Plant Physiol Biochem 34: 223-227 (1996).

85. Paris N, Rogers SW, Jiang L, Kirsch T, Beevers L, Phillips TE, Rogers JC: Molecular cloning and further characterization of a probable plant vacuolar sorting receptor. Plant Physiol 115: 29-39 (1997).

86. Paris N, Stanley CM, Jones RL, Rogers JC: Plant cells contain two functionally distinct vacuolar compartments. Cell 85: 563-572 (1996).

87. Pfeffer SR, Rothman JE: Biosynthetic protein transport and sorting by the endoplasmic reticulum and Golgi. Annu Rev Biochem 56: 828-852 (1987).

88. Piper RC, Cooper AA, Yang H, Stevens TH: VPS27 controls vacuolar and endocytic traffic through a prevacuolar compartment in Saccharomyes cerevisiae. J Cell Biol 131: 603-617 (1995).

89. Raymond CK, Roberts CJ, Moore K, Howald I, Stevens TH: Biogenesis of the vacuole in Saccharomyces cerevisiae. Int Rev Cytol 139: 59-120 (1992).

90. Robinson DG, Bäumer M, Hinz G, Hohl I: Vesicle transfer of storage proteins to the vacuole: The role of the Golgi apparatus and multivesicular bodies. J Plant Physiol, in press (1998).

91. Robinson DG, Hinz G: Vacuole biogenesis and protein transport to the plant vacuole: a comparison with the yeast vacuole and the mammalian lysosome. Protoplasma 197: 1-25 (1997).

92. Robinson DG, Hoh B, Hinz G, Jeong B-K: One vacuole or two vacuoles: do protein storage vacuoles arise de novo during pea cotyledon development? J Plant Physiol 145: 654-664 (1995).

93. Rogers SW, Burks M, Rogers JC: Monoclonal antibodies to barley aleurain and homologues from other plants. Plant J 11: 1359-1368 (1997).

94. Rosahl S, Schell J, Willmitzer L: Expression of a tuberspecific storage protein in transgenic tobacco plants: demonstration of an esterase activity. EMBO J 6: 1155-1159 (1987).

95. Runeberg-Roos P, Törmäkangas K, Östman A: Primary structure of a barley-grain aspartic proteinase: a plant aspartic proteinase resembling mammalian cathepsin D. Eur J Biochem 202: 1021-1027 (1991).

96. Saalbach G, Jung R, Kunze G, Saalbach I, Adler K, Müntz K: Different legumin protein domains act as vacuolar targeting signals. Plant Cell 3: 695-708 (1991).

97. Schroeder MR, Borkhsenious ON, Matsuoka K, Nakamura $\mathrm{K}$, Raikhel NV: Colocalization of barley lectin and sporamin in vacuoles of transgenic tobacco plants. Plant Physiol 101: 451-458 (1993).

98. Scott SV, Baba M, Ohsumi Y, Klionsky DJ: Aminopeptidase I is targeted to the vacuole by a nonclassical vesicular mechanism. J Cell Biol 138: 37-44 (1997).

99. Sebastiani FL, Farrell LB, Vasquez M, Beachy RN: Conserved amino acid sequences among plant proteins sorted to protein bodies and plant vacuoles. Can they play a role in protein sorting? Eur J Biochem 199: 441-450 (1991).

100. Shimada T, Kuroyanagi M, Nishimura M, Hara-Nishimura I: A pumpkin $72-\mathrm{kDa}$ membrane protein of precursoraccumulating vesicles has characteristics of a vacuolar sorting receptor. Plant Cell Physiol 38: 1414-1420 (1997). 
101. Sonnewald U, Sturm A, Chrispeels MJ, Willmitzer L: Targeting and glycosylation of patatin the major potato tuber protein in leaves of transgenic tobacco. Planta 179: 171-180 (1989).

102. Sonnewald U, von Schaewen A, Willmitzer L: Expression of mutant patatin protein in transgenic tobacco plants: role of glycans and intracellular location. Plant Cell 2: 345-355 (1990).

103. Staab JF, Ginkel DL, Rosenberg GB, Munford RS: A saposin-like domain influences the intracellular localization, stability, and catalytic activity of human acyloxyacyl hydrolase. J Biol Chem 269: 23736-23742 (1994).

104. Staehelin LA: The plant ER: a dynamic organelle composed of a large number of discrete functional domains. Plant J 11: 1151-1165 (1997).

105. Staehelin LA, Moore I: The plant Golgi apparatus: structure, functional organization and trafficking mechanisms. Annu Rev Plant Physiol Plant Mol Biol 46: 261-288 (1995).

106. Staswick PE: Storage proteins of vegetative plant tissues Annu Rev Plant Physiol Plant Mol Biol 45: 303-322 (1994).

107. Sticher L, Hinz U, Meyer AD, Meins F: Intracellular transport and processing of a tobacco vacuolar $\beta$-1,3-glucanase. Planta 188: 559-565 (1992)

108. Sturm A, Chrispeels MJ: Correct glycosylation, Golgiprocessing, and targeting to protein bodies of the vacuolar protein phytohemagglutinin in transgenic tobacco. Planta 175: 170-183 (1988)

109. Swanson SJ, Bethke PC, Jones RL: Barley aleurone cells contain two types of vacuoles: characterization of lytic organelles using fluorescent probes. Plant Cell 10: 685-698 (1998).

110. Tague BW, Chrispeels MJ: The plant vacuolar protein, phytohemagglutinin, is transported to the vacuole of transgenic yeast. J Cell Biol 105: 1971-1979 (1987).

111. Tague BW, Dickinson CD, Chrispeels MJ: A short domain of the plant vacuolar protein phytohemagglutinin targets invertase to the yeast vacuole. Plant Cell 2: 533-546 (1990).

112. Törmäkangas K: Structure, expression and intracellular targeting of barley aspartic proteinase. Ph.D. thesis, Institute of Biotechnology and Department of Biosciences, University of Helsinki, Finland (1997).
113. Tranbarger TJ, Franceschi VR, Hildebrand DF, Grimes HD The soybean 94-kilodalton vegetative storage protein is a lipoxygenase that is localized in paraveinal mesophyll cell vacuoles. Plant Cell 3: 973-987 (1991).

114. Vida TA, Huyer G, Emr SD: Yeast vacuolar proenzymes are sorted in the late Golgi complex and transported to the vacuole via a prevacuolar endosome-like compartment. J Cell Biol 121: 1245-1256 (1993).

115. Vitale A, Chrispeels M: Transient N-acetylglucosamine in the biosynthesis of phytohemagglutinin: attachment in the Golgi apparatus and removal in the protein bodies. J Cell Biol 99: 133-140 (1984).

116. Vitale A, Chrispeels MJ: Sorting of proteins to the vacuoles of plant cells. BioEssays 14: 151-160 (1992).

117. von Heijne G: A new method for predicting signal sequence cleavage sites. Nucl Acids Res 14: 4683-4690 (1986).

118. von Schaewen A, Chrispeels MJ: Identification of vacuolar sorting information in phytohemagglutinin, an unprocessed vacuolar protein. J Exp Bot 44 (Suppl): 339-342 (1993).

119. Weig A, Deswarte C, Chrispeels MJ: The major intrinsic protein family of Arabidopsis has 23 members that form three distinct groups with functional aquaporins in each group. Plant Physiol 114: 1347-1357 (1997).

120. Wilkins TA, Bednarek SY, Raikhel NV: Role of propeptide glycan in post-translational processing and transport of barley lectin to vacuoles in transgenic tobacco. Plant Cell 2: 310-313 (1990).

121. Wink M: The plant vacuole: A multifunctional compartment. J Exp Bot 44 (Suppl): 231-246 (1993).

122. Young NM, Watson DC, Yaguchi M, Adar R, Arango R, Rodriguez-Arango E, Sharon N, Blay PKS, Thibault P: Cterminal post-translational proteolysis of plant lectins and their recombinant forms expressed in Escherichia coli: characterization of 'ragged ends' by mass spectrometry. J Biol Chem 270: 2563-2570 (1995).

123. Zhu Y, Conner GE: Intermolecular association of lysosomal protein precursors during biosynthesis. J Biol Chem 269: 3846-3851 (1994). 